\title{
BMJ Open The impact of complaints procedures on the welfare, health and clinical practise of 7926 doctors in the UK: a cross-sectional survey
}

\author{
Tom Bourne, ${ }^{1,2,3}$ Laure Wynants, ${ }^{4,5}$ Mike Peters, ${ }^{6}$ Chantal Van Audenhove, ${ }^{7}$ \\ Dirk Timmerman, ${ }^{2,3}$ Ben Van Calster, ${ }^{2}$ Maria Jalmbrant ${ }^{8}$
}

To cite: Bourne T, Wynants L, Peters M, et al. The impact of complaints procedures on the welfare, health and clinical practise of 7926 doctors in the UK: a cross-sectional survey. BMJ Open 2015;4:e006687. doi:10.1136/bmjopen-2014006687

- Prepublication history and additional material is available. To view please visit the journal (http://dx.doi.org/ 10.1136/bmjopen-2014006687).

Received 19 September 2014 Revised 9 December 2014 Accepted 10 December 2014

CrossMark

For numbered affiliations see end of article.

Correspondence to Professor Tom Bourne; tbourne@imperial.ac.uk

\section{ABSTRACT}

Objectives: The primary aim was to investigate the impact of complaints on doctors' psychological welfare and health. The secondary aim was to assess whether doctors report exposure to a complaints process is associated with defensive medical practise.

Design: This was a cross-sectional anonymous survey study. Participants were stratified into recent/current, past, no complaints. Each group completed tailored versions of the survey.

Participants: 95636 doctors were invited to participate. A total of $10930(11.4 \%)$ responded, 7926 $(8.3 \%)$ completed the full survey and were included in the complete analysis.

Main outcome measures: Anxiety and depression were assessed using the standardised Generalised Anxiety Disorder scale and Physical Health Questionnaire. Defensive practise was evaluated using a new measure. Single-item questions measured stressrelated illnesses, complaints-related experience, attitudes towards complaints and views on improving complaints processes.

Results: $16.9 \%$ of doctors with current/recent complaints reported moderate/severe depression (relative risk (RR) 1.77 (95\% Cl 1.48 to 2.13) compared to doctors with no complaints $(9.5 \%))$. Fifteen per cent reported moderate/severe anxiety (RR $=2.08(95 \% \mathrm{Cl}$ 1.61 to 2.68) compared to doctors with no complaints $(7.3 \%))$. Distress increased with complaint severity, with highest levels after General Medical Council (GMC) referral (26.3\% depression, $22.3 \%$ anxiety). Doctors with current/recent complaints were $2.08(95 \% \mathrm{Cl} 1.61$ to 2.68) times more likely to report thoughts of selfharm or suicidal ideation. Most doctors reported defensive practise: $82-89 \%$ hedging and $46-50 \%$ avoidance. Twenty per cent felt victimised after whistleblowing, 38\% felt bullied, $27 \%$ spent over 1 month off work. Over $80 \%$ felt processes would improve with transparency, managerial competence, capacity to claim lost earnings and action against vexatious complainants.

Conclusions: Doctors with recent/current complaints have significant risks of moderate/severe depression, anxiety and suicidal ideation. Morbidity was greatest in cases involving the GMC. Most doctors reported practising defensively, including avoidance of

\section{Strengths and limitations of this study}

- This is one of the largest reports on this subject with 10930 respondents, 7926 of whom completed the survey. Critically, respondents were guaranteed at the outset that their responses would be anonymous and untraceable, so we think the respondents are likely to have been open about their opinions.

- We have obtained quantitative data on mental well-being using validated questionnaires.

- The main limitation of the study was the overall response rate of $11.4 \%$. Accordingly, the findings must be interpreted with caution due to the possibility of ascertainment bias. On the other hand, doctors were being asked to comment on their regulators, and those most traumatised by the complaints process may have avoided engaging with the survey. Doctors who have been erased from the register or changed profession would not have been contacted. It is also important to note that the cross-sectional design does not enable causation to be elucidated.

- We collected responses from doctors who have not experienced a complaint but observed the impact on others. This means that the 'no complaints' group may have more psychological morbidity than if doctors could be isolated from complaints processes completely. This may result in relative risks of the paper being underestimated.

- Some questions involved remembering past events and the possibility of recall bias must also be considered. There were also missing responses for a number of questions. However, this was dealt with using multiple imputation. We are reassured that no major differences between the conclusions would be drawn using complete cases compared to those where data was missing and imputed.

procedures and high-risk patients. Many felt victimised as whistleblowers or reported bullying. Suggestions to improve complaints processes included transparency and managerial competence. 


\section{INTRODUCTION}

In the United Kingdom (UK), the General Medical Council (GMC) acts as the regulator and sets standards that doctors are expected follow. It has the power to warn, suspend, restrict the practise of doctors or permanently remove them from the register. These powers are established under the Medical Act (1983).

It was recently disclosed that 114 doctors have died between 2005 and 2013 while involved in GMC fitness to practise proceedings. In parallel to this, between 2011 and 2012, the number of doctors referred to the GMC increased by $18 \%{ }^{1}$ Although most doctors referred to the GMC have their case closed at triage or have no action taken, ${ }^{2}$ there can be harrowing consequences for some doctors who go through a GMC investigation. ${ }^{3}$

However, the GMC represents only the tip of the iceberg of the complaints system. This includes formal and informal hospital internal enquiries, serious untoward incident (SUI) investigations, and disputes with managers and colleagues. While there are some data relating to how doctors respond to GMC investigations, to the best of our knowledge there are no studies addressing the issue of complaints procedures below this level in the UK. For many doctors, the prospect of facing a complaint or professional dispute causes them significant stress. This can manifest itself in how they perform in clinical practise and/or in their personal life, and may lead to physical and psychological symptoms.

Clearly, complaints and investigations when things go wrong are part of the checks and balances that should ensure appropriate oversight of a doctor's performance, the overall aim being to protect patients and maintain appropriate clinical standards. However, the regulatory burden and stress associated with a complaints process may not lead to the outcomes that are desired.

In a previous study of surgeons surveyed in the United States (US), malpractise litigation was significantly associated with burnout, depression and suicidal ideation. ${ }^{4}$ There are also data to suggest that medical errors are associated with depression and loss of empathy in the physician responsible. ${ }^{5}$ None of these outcomes are likely to improve patient care. A further study has shown suicidal ideation in over $6 \%$ of US surgeons, over twice the background rate in the population. In this study, burnout, depression and involvement in a recent medical error were strongly and independently associated with suicidal ideation, after controlling for other personal and professional characteristics. Most surgeons in this study were reluctant to seek professional help due to concerns that there may be an impact on their career. ${ }^{6}$

In a study published in the $B M J$, Jain and Ogden ${ }^{7}$ described the impact of patient complaints on general practitioners in the UK and reported an association with anger, depression and suicide. It is important to note that they also described clinicians involved in complaints practising medicine more defensively. Such practise may be broadly categorised into 'hedging' and 'avoidance'.
Hedging is when doctors are overcautious, leading, for example, to overprescribing, referring too many patients or over investigation. Avoidance includes not taking on complicated patients and avoiding certain procedures or more difficult cases.

The primary aim of this study was to investigate the psychological welfare of doctors who have observed or experienced past and/or current complaints. The secondary aim of the study was to assess whether being involved in or witnessing a complaints process leads to doctors reporting that they practise medicine defensively.

\section{METHODS}

\section{Design}

The study used a cross-sectional survey design where participants were streamed into three groups: current/ recent complaint (on-going or resolved within the last 6 months), past complaint (resolved more than 6 months ago) and no complaints. Each group completed a slightly different version of the questionnaire. Participants in the current complaints and no complaints group were asked about their current mood and health whereas the past complaints group were also asked to respond about their mood and health at the time of the complaint.

All participants consented to participating in the study before they completed the questionnaire. The study was self-funded, and no external funding was sought.

\section{Participants}

The British Medical Association (BMA) is an apolitical professional association and independent trade union that represents doctors and medical students in the UK; membership is voluntary. Members of the BMA in November 2012 who had pre-consented to being contacted for research purposes were invited to participate $(\mathrm{n}=95636)$. They were emailed a link to an online encrypted questionnaire using Survey Monkey and an information sheet describing the study. Participants were guaranteed that their responses were anonymous and untraceable. The survey remained open for 2 weeks and three reminders were sent out about the study during this time. A total of $10930(11.4 \%)$ participants responded to the survey. Of these, $696(6.4 \%)$ were excluded as they only completed the demographics section, and $121(1.1 \%)$ participants were excluded because a technical error meant that they were given the wrong sections to complete. A further 2187 (20\%) participants completed the demographics section and indicated whether they had had a complaint, they were partially included in the analysis (as part of sample 1). A total of $7926(72.5 \%)$ participants completed the survey (sample 2). Of these, 1380 omitted some sections of the survey but were included in the full analysis. Demographic information in relation to both samples is shown in table 1.

In order to check that our sample was representative, we compared our study population with the total BMA 
Table 1 Demographic information relating to sample 1 and 2 in the study

\begin{tabular}{|c|c|c|c|}
\hline Age & $\begin{array}{l}\text { Total BMA membership } \\
\text { consented for research (\%) }\end{array}$ & $\begin{array}{l}\text { Sample } 1 \\
(n=10113)(\%)\end{array}$ & $\begin{array}{l}\text { Sample } 2 \\
(n=7926)(\%)\end{array}$ \\
\hline Up to 25 & 17.8 & 1.4 & 1.4 \\
\hline $26-29$ & 9.0 & 5.1 & 5.5 \\
\hline 30-34 & 9.6 & 8.6 & 8.8 \\
\hline 35-39 & 10.3 & 11.0 & 11.0 \\
\hline $40-44$ & 10.3 & 13.5 & 13.1 \\
\hline $45-49$ & 10.8 & 16.9 & 16.8 \\
\hline $50-54$ & 10.3 & 18.8 & 18.8 \\
\hline $55-59$ & 8.1 & 14.6 & 14.7 \\
\hline $60-64$ & 5.0 & 6.6 & 6.4 \\
\hline $65-69$ & 3.0 & 2.5 & 2.6 \\
\hline Over 69 & 5.9 & 1.1 & 1.0 \\
\hline Gender & 46.3 Female & 47.5 Female & 47.5 Female \\
\hline \multicolumn{4}{|l|}{ Place of qualification } \\
\hline UK & 80.1 & 80.7 & 81.2 \\
\hline India & 8.2 & 6.6 & 6.2 \\
\hline Pakistan & 2.2 & 1.2 & 1.2 \\
\hline Ireland & 0.9 & 1.4 & 1.4 \\
\hline Nigeria & 1.1 & 1.2 & 1.2 \\
\hline Germany & 0.7 & 1.1 & 1.2 \\
\hline South Africa & 0.7 & 0.8 & 0.8 \\
\hline Other & 6.2 & 6.9 & 6.9 \\
\hline \multicolumn{4}{|l|}{ Ethnicity } \\
\hline White British & 67.6 & 77.6 & 78.2 \\
\hline Asian or Asian British & 23.3 & 16.6 & 15.8 \\
\hline Black or Black British & 3.5 & 2.3 & 2.3 \\
\hline Chinese or Chinese British & 2.9 & 1.3 & 1.3 \\
\hline Mixed & 2.7 & 2.3 & 2.3 \\
\hline \multicolumn{4}{|l|}{ Grade: } \\
\hline Academics & 2.1 & 1.2 & 1.3 \\
\hline Consultants & 27.2 & 37.1 & 36.5 \\
\hline General practice & 26.0 & 38.4 & 37.8 \\
\hline Junior doctors & 26.4 & 15.7 & 16.5 \\
\hline SASC & 5.3 & 5.8 & 6.11 \\
\hline Retired & 8.6 & 0.7 & 0.7 \\
\hline Other or no answer & 4.4 & 1.0 & 1.1 \\
\hline
\end{tabular}

membership database (see table 1). This showed that our sample was broadly representative in terms of gender $(46.3 \%$ females in the BMA membership database compared to $47.5 \%$ females in samples 1 and 2) and place of qualification $(80.1 \%$ qualified in the UK in the BMA population compared to $80.7 \%$ in sample 1 and $81.2 \%$ in sample 2). Our study population consisted of more doctors in the 35-59 age range $(49.8 \%$ in the BMA population compared to $74.8 \%$ in sample 1 and $73.4 \%$ in sample 2), ethnic minorities were underrepresented $(32.4 \%$ in the BMA population compared to $22.4 \%$ in sample 1 and $21.8 \%$ in sample 2) and consultants and general practitioners (GPs) were overrepresented (27.2\% were consultants and $26 \%$ were GPs in the BMA population compared to $37.1 \%$ and $38.4 \%$ in sample 1 and $36.5 \%$ and $37.8 \%$ in sample 2, respectively), while junior doctors and retired doctors were under-represented (26.4\% were juniors and $8.6 \%$ were retired in the BMA population compared to $15.7 \%$ and
$0.7 \%$ in sample 1 and $16.5 \%$ and $0.7 \%$ in sample 2 , respectively).

\section{Measures}

A pilot of the questionnaire was trialled on 20 medical doctors of varying grades and specialties, and their feedback, was incorporated in the questionnaire design (see details below). In total, 108 questions were asked to the no complaints group and 179 questions were asked to both the complaints groups. Based on filling in trial questionnaires, we estimate the time required to complete the questionnaire was approximately $30 \mathrm{~min}$. The questionnaire is included as supplementary online information (see online supplementary file 1) or can be reviewed by using the following link: https://www. surveymonkey.com/s/P55KH5P

Having completed 13 items obtaining demographic information (including age, specialty, gender, marital status, ethnicity, place of training and details about their 
employment), participants were separated into three streams based on whether they had (1) a current/recent complaint (within the past 6 months), (2) past complaint or (3) no current or past complaints.

The different types of complaints or investigations that were considered in the study are outlined below:

Informal: an informal complaint usually involves a patient speaking directly to the people involved in their care in order to resolve their concerns. It can be escalated to a formal complaint if not resolved locally.

Formal: this is a written complaint, usually to the chief executive or an employing organisation, which triggers an investigation and often requires a written response within a set time period and may lead to disciplinary action or referral to the GMC.

SUI: the definition of an SUI is wide ranging and includes an unexpected death, poor clinical outcome, a hazard to public health, a trend leading to reduced standards of care, damage to reputation or confidence in a service or adverse media coverage or public concern about an organisation. The aim is to prevent recurrence of the adverse event, but may lead to disciplinary action for individuals or referral to the GMC.

GMC: a complaint can be made about a doctor for issues ranging from personal behaviour outside work to clinical concerns about their practise. The GMC reviews cases and has the power to suspend doctors from practise during an investigation. This may lead to a warning, or referral to a tribunal that has the power to restrict a doctor's practise or impose working under supervision, suspension from the medical register or removal of a doctor from the register permanently. The GMC may also issue warnings and undertakings to doctors to change aspects of their behaviour or practise.

All participants completed the following sections (although some individual items varied in the different streams):

Experience of complaint: Participants in both complaints groups were asked 75 questions about their complaint (s) generated from Bark $e t a l^{8}$ and the pilot study. This included their total number of complaints and the most significant complaint, and was followed by a series of questions about the most serious complaint if they had had more than one, including the reason for the complaint, the origin, the duration, the outcome, the cost (ie, any leave taken, the estimated financial cost) and the level of support sought and obtained during the complaint. Participants who had been referred to the GMC were also asked to rate how stressful they found each aspect of the procedure. While the majority of the questions used a 5-point scale, some questions were qualitative and a few were yes/no.

Attitudes towards complaints: All groups were asked 10 questions using a 5-point scale generated from the pilot study about their attitudes toward complaints, the causes of complaints and their perceived threat of future complaints. The no complaints group was asked 11 additional questions about their attitudes towards the complaints process (eg, "I believe that complaints are reasonably dealt with") and how well they perceive that they would be supported in the event of a complaint made against them (eg, "If I had a complaint made against me, I am confident that my management would support me").

Suggestions to improve the complaints process. All groups were asked to rate different suggestions on how to improve the complaints process on 11 5-point items. These proposals were generated from the pilot study.

Medical history: The presence of common stress-related illnesses at the time of the complaint or currently were measured using 12 items, including recurring infections, gastrointestinal, sleep, cardiovascular and mood problems. ${ }^{9}{ }^{10}$ In addition, questions were asked about selfreported drug and alcohol use, as well as life stressors at the time of current and of past complaints.

Defensive medical practise: Twenty items measuring current defensive medical practise were generated from a literature review. ${ }^{10-12}$ Twelve additional items were generated from the pilot study ( 5 for the no complaints group). Items were rated either on a 5-point scale or on a yes/no response.

Depression: The Physical Health Questionnaire $\left(P H Q-9^{13}\right)$ is a well-known standardised screening measure assessing the presence and severity of depression. It has been used across a wide range of populations and has demonstrated good psychometric properties. Respondents were considered depressed if they scored 10 or more on the PHQ-9. ${ }^{14}$

Anxiety: The Generalised Anxiety Disorder scale (GAD-7 ${ }^{15}$ ) is a standardised screening measure assessing the presence and severity of GAD. The GAD-7 is also moderately good at identifying panic disorder, social anxiety disorder and post-traumatic stress disorder. It has been used across a wide range of populations and has demonstrated good psychometric properties. Respondents were considered anxious if they scored 10 or more on the GAD-7. ${ }^{15}$

Life satisfaction: Life satisfaction was assessed with 10 items using a 6-point scale asking about satisfaction-dissatisfaction with marriage, career, recreation/leisure, self/family and life satisfaction/optimism.

\section{Statistical analysis}

For the purpose of this paper, we have limited ourselves to analysis of psychological welfare and health (ie, anxiety, depression, stress-related illness), defensive practise, culture, time off work and suggestions for improving the complaints process. To summarise the 15 items measuring defensive practise, an exploratory factor analysis was conducted, which identified two underlying factors. The first involves overinvestigation and overly cautious management, which we have termed 'hedging' (9 items, including, for example, 'carried out more tests than necessary', 'referred patient for second opinion more than necessary' and 'admitted patients to the hospital when the patient could have been discharged home safely or managed as an outpatient', Cronbach's 
$\alpha=0.92$ ). The second involves avoiding difficult aspects of patient treatment, which we termed 'avoidance' (3 items, 'stopped doing aspects of my job', 'not accepting high risk patients in order to avoid possible complications' and 'avoiding a particular type of invasive procedure', Cronbach's $\alpha=0.77$ ). Owing to strongly skewed distributions, the sumscores 'hedging' and 'avoidance' were analysed both as dichotomous (any hedging $(>0)$ / avoidance $(>0)$ versus no hedging (0)/avoidance $(0)$ ) and ordinal variables (never $(0)$, rarely (hedging $1-12$, avoidance 1-4), sometimes (hedging 13-24, avoidance 5-8) or often (hedging 25-36, avoidance 9-12) displaying hedging or avoidance behaviour.)

The statistical analysis mainly consisted of descriptive analyses. Cross-tabulations of psychological welfare and defensive practise indicators have been made and relative risks were computed to investigate the relationship between complaint group and psychological welfare or defensive practise indicators. Additionally, means within the complaint groups and mean differences have been computed for continuous variables such as depression and anxiety. Asymptotic 95\% CIs were computed for relative risks and mean differences. Unpooled SEs of the mean difference were used when necessary. Proportions and their 95\% CIs were also computed for feeling bullied during the investigation, feeling victimised because of whistleblowing and the amount of time spent off work. Proportions were computed to investigate the amount of support of respondents to various proposed actions to improve the complaints process.

As the primary aim of this study was to investigate the impact of complaints on the psychological welfare and health of doctors, a logistic regression analysis was performed to assess the relationship between moderate to severe depression and receiving a complaint, while controlling for predefined confounders (age, gender, being in a relationship, being White British and medical specialty). Interactions of complaint with the confounders were included if necessary $(\alpha=0.001)$. Proportional odds logistic models were constructed to investigate whether hedging or avoidance are associated with characteristics of the complaint process (length of investigation, timing of complaint, outcome of investigation, origin of complaint, type of complaint). For hedging and avoidance, all two-way interactions were of interest and were included if necessary $(\alpha=0.001)$. We checked linearity assumptions, the presence of multicollinearity, the presence of outliers and the proportional odds assumption when necessary.

There was substantial item non-response. For key variables such as depression, anxiety, hedging and avoidance, non-response was approximately 20\%. Missing data was addressed by performing multiple imputation. ${ }^{16}$ Missing responses were replaced by 100 plausible values based on available responses to other questions, leading to 100 completed data sets that represent the uncertainty about the right value to impute. For composite scales (depression, anxiety and hedging), a two-step approach to imputation was used to decrease the computational burden and to make appropriate use of the available answers to separate items, first imputing the respondent's mean of non-missing items if at least $80 \%$ of the items of the composite scale were nonmissing, followed by multiple imputation (MI) at the scale level for the remaining individuals. For avoidance, the three items were individually imputed. MI was performed using chained equations (MICE) ${ }^{16}$ with 10 iterations. After MI, each completed data set was analysed separately and results combined using standard Rubin's rules. ${ }^{17}$ To assess the impact of item non-response, we performed a sensitivity analysis comparing the results of the complete case analysis to the results after MI, which assumes missingness at random. Additionally, MI assuming missingness not at random (MNAR also known as informative missings) was considered for key variables depression, anxiety, hedging and avoidance. ${ }^{17}$ Since these variables are based on responses to sensitive questions, informative missingness is plausible. As a missingness mechanism we assumed that those respondents with missingness might have been more anxious or depressed, or more likely to display hedging behaviour or avoidance. More details on the MNAR analysis can be found in the online supplementary file.

The data were analysed using SAS (V.9.3, SAS Institute, Cary, North Carolina, USA). MIs were performed using IVEware (http://www.isr.umich.edu/src/ smp/ive/). ${ }^{18}$

\section{RESULTS}

\section{Psychological welfare and health}

Overall, $16.9 \%$ of doctors with recent or ongoing complaints reported clinically significant symptoms of moderate to severe depression (table 2). Doctors in this group were at increased risk of depression compared to those with a past complaint $(7.8 \%)$ or no personal experience of a complaint $(9.5 \%$; RR $=1.77,95 \%$ CI 1.48 to 2.13). This was the case even when controlling for the effects of gender, age (cubic effect), being in a relationship (yes/no), being White British (yes/no) and medical specialty. The effect of having a recent or current complaint depends on gender. When there has been no complaint, men tend to be less likely to be depressed than women ( $\mathrm{OR}=0.76,95 \%$ CI 0.54 to 1.09 ), but a recent or current complaint has a higher impact on men than on women (OR women $=1.72,95 \%$ CI 1.28 to 2.30 ; OR men $=2.86,95 \%$ CI 2.04 to 4.01 ). Within the PHQ-9, doctors with an ongoing or recent complaint $(9.7 \%)$ were twice as likely as doctors with no complaints $(4.7 \%)$ to report having thoughts of self-harm or suicidal ideation ( $R R=2.08,95 \%$ CI 1.61 to 2.68 ; see table 2). The sensitivity analysis shows that this conclusion holds under various assumed missingness mechanisms (see online supplementary figure S1 and table S1).

Moreover, $15 \%$ of doctors in the recent complaints group reported clinically significant levels of anxiety on 


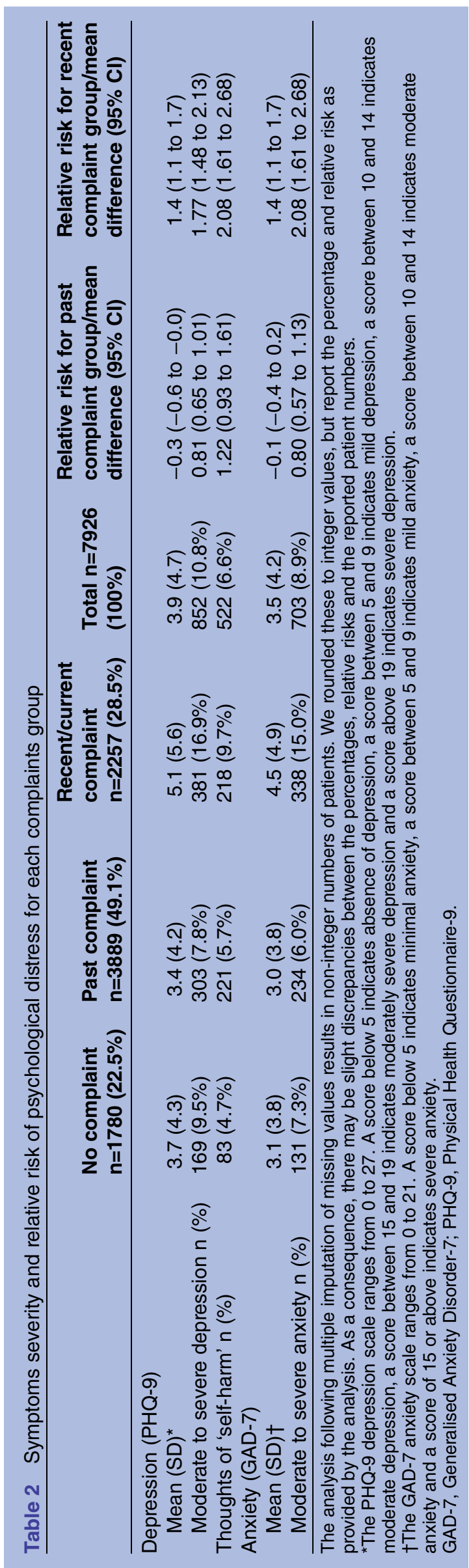

the GAD-7, which is twice as likely as doctors who have no complaints (see table 2, 7.3\%, RR=2.08, 95\% CI 1.61 to 2.68). This conclusion also holds under various assumed missingness mechanisms (see online supplementary file 1 and table S2).

The level of psychological distress was related to the type of complaints procedure. Doctors going through a GMC referral reported the highest levels of depression $(26.3 \%)$, anxiety $(22.3 \%)$ and thoughts of self-harm $(15.3 \%)$ compared to SUIs $(16.1 \%, 15.3 \%$ and $9.3 \%)$, formal complaints $(15.6 \%, 13.5 \%$ and $9 \%)$ and informal complaints (12\%, $12 \%$ and $6.4 \%$, respectively) (table 3$)$.

When asked directly, using a single item scale, doctors were 3.78 (95\% CI 2.68 to 5.32) times more likely to report the presence of suicidal thoughts while going through a current or recent complaint compared to doctors who had no complaints (table 4).

Doctors who have experienced either a recent or past complaint reported higher levels of health problems at the time of the complaint compared to the no complaint group. These included gastrointestinal problems, subjective anxiety and depression, anger, other mental health problems, insomnia, relationship problems and frequent headaches. Doctors in the current complaints group also reported higher levels of cardiovascular problems (table 4).

\section{Defensive practise}

Overall, $84.7 \%$ of doctors with a recent and $79.9 \%$ with a past complaint reported changing the way they practised medicine as a result of the complaint; $72.7 \%$ of doctors with no previous complaint reported changing their practise after having observed a colleague's experience of a complaint (table 5).

There were $88.6 \%$ of doctors with a recent or current complaint and $82.6 \%$ of those with a past complaint who displayed hedging behaviour; $81.7 \%$ of doctors with no previous complaints reported hedging. The sensitivity analysis revealed that under the MNAR assumption, the conclusion still holds that doctors in the recent or current complaint group display more hedging behaviour than those in the no complaints group, but also doctors with a past complaint display considerably more hedging behaviour (see online supplementary figure 1 table S3).

$49.8 \%$ of doctors with a recent or current complaint, $42.9 \%$ of doctors with a past complaint and $46.1 \%$ of doctors with no personal experience of a complaint reported avoidance behaviour having observed a colleague's experience of a complaint. Although the results from the complete case analysis support the conclusion that mostly doctors in the recent and current complaint group display avoidance behaviour, the results from the analysis under the MNAR assumption suggest that it is those with a past complaint who display most avoidance behaviour (see online supplementary figure 1 table S4).

The multivariable proportional odds analysis indicated that the odds of more severe hedging are higher for 
Table 3 Psychological distress within the recent/on-going complaints group by complaint that had the most impact

\begin{tabular}{|c|c|c|c|c|c|}
\hline & $\begin{array}{l}\text { Informal } \\
\text { complaint } \\
n=362(16 \%)\end{array}$ & $\begin{array}{l}\text { Formal Complaint } \\
\mathrm{n}=1196(53 \%)\end{array}$ & $\begin{array}{l}\text { SUI } \\
n=280(12.4 \%)\end{array}$ & $\begin{array}{l}\text { GMC referral } \\
\mathrm{n}=374(16.6 \%)\end{array}$ & $\begin{array}{l}\text { No complaint } \\
\mathrm{n}=1780(22.5 \%)\end{array}$ \\
\hline \multicolumn{6}{|l|}{ Depression (PHQ-9) } \\
\hline Mean (SD)* & $4.2(5.0)$ & $4.8(5.4)$ & $5.1(5.6)$ & $6.6(6.7)$ & $3.7(4.3)$ \\
\hline $\begin{array}{l}\text { Moderate to severe } \\
\text { depression } n(\%)\end{array}$ & $45(12.0 \%)$ & $190(15.6 \%)$ & $46(16.1 \%)$ & $100(26.3 \%)$ & $169(9.5 \%)$ \\
\hline Thoughts of 'self-harm' n (\%) & $24(6.4 \%)$ & $110(9.0 \%)$ & 27 (9.3\%) & $58(15.3 \%)$ & $83(4.7 \%)$ \\
\hline \multicolumn{6}{|l|}{ Anxiety (GAD-7) } \\
\hline Mean (SD)† & $3.8(4.3)$ & $4.4(4.7)$ & $4.7(5.1)$ & $5.7(5.7)$ & $3.1(3.8)$ \\
\hline $\begin{array}{l}\text { Moderate to severe anxiety } \\
\mathrm{n}(\%)\end{array}$ & $44(12.0 \%)$ & $165(13.5 \%)$ & $44(15.3 \%)$ & $85(22.3 \%)$ & $131(7.3 \%)$ \\
\hline \multicolumn{6}{|c|}{$\begin{array}{l}\text { The analysis following multiple imputation of missing values results in non-integer numbers of patients. We rounded these to integer values, } \\
\text { but report the percentage and relative risk as provided by the analysis. As a consequence, there may be slight discrepancies between the } \\
\text { percentages and the reported patient numbers. } \\
\text { *The PHQ-9 depression scale ranges from } 0 \text { to } 27 \text {. A score below } 5 \text { indicates absence of depression, a score between } 5 \text { and } 9 \text { indicates mild } \\
\text { depression, a score between } 10 \text { and } 14 \text { indicates moderate depression, a score between } 15 \text { and } 19 \text { indicates moderately severe depression } \\
\text { and a score above } 19 \text { indicates severe depression. } \\
\text { †The GAD-7 anxiety scale ranges from } 0 \text { to } 21 \text {. A score below } 5 \text { indicates minimal anxiety, a score between } 5 \text { and } 9 \text { indicates mild anxiety, a } \\
\text { score between } 10 \text { and } 14 \text { indicates moderate anxiety and a score of } 15 \text { or above indicates severe anxiety } \\
\text { GAD-7, Generalised Anxiety Disorder-7; PHQ-9, Physical Health Questionnaire-9; SUI, serious untoward incident. }\end{array}$} \\
\hline
\end{tabular}

people with a recent or ongoing complaint than for those with a past complaint (OR $1.3395 \%$ CI 1.19 to 1.49 ; table 6$)$. The odds of hedging slightly increased with the length of time of the investigation (OR 1.01 per month, $95 \%$ CI 1.00 to 1.01$)$. Hedging was increased when retraining was imposed (OR 1.62, 95\% CI 0.84 to 3.13) and decreased when the doctor was suspended from practise (OR $0.56,95 \%$ CI 0.26 to 1.18 ). The odds of hedging also decreased when the complaint came from medical colleagues (OR $0.67,95 \%$ CI 0.53 to $0.86)$. There was evidence of an interaction between the type of most serious complaint experienced and whether or not the complaint came from a patient (see online supplementary figure S1). Hedging was higher when the complaint came from a patient, this was most clear for informal $(\mathrm{OR}=3.16,95 \%$ CI 2.17 to 4.58$)$ and formal complaints $(\mathrm{OR}=2.18,95 \%$ CI 1.67 to 2.85). When the complaint did not come from a patient, hedging was higher for formal complaints, SUI's and GMC referrals compared to informal complaints $(\mathrm{OR}=1.52,95 \%$ CI 1.03 to $2.24, \mathrm{OR}=2.10,95 \%$ CI 1.31 to 3.35 and $\mathrm{OR}=1.78,95 \%$ CI 1.16 to 2.71 , respectively).

Table 4 Psychosomatic health for each of the complaints groups

\begin{tabular}{|c|c|c|c|c|}
\hline & $\begin{array}{l}\text { No complaint } \\
n=1780(22.5 \%)\end{array}$ & $\begin{array}{l}\text { Recent or current } \\
\text { complaint } \\
\mathrm{n}=2257(28.5 \%)\end{array}$ & $\begin{array}{l}\text { Past complaint } \\
n=3889(49.1 \%)\end{array}$ & $\begin{array}{l}\text { RR recent or current } \\
\text { versus no complaint }\end{array}$ \\
\hline $\begin{array}{l}\text { Cardiovascular problems } \\
\text { (eg, high blood pressure, angina, } \\
\text { heart attack) }\end{array}$ & $124(7)$ & $280(12.4)$ & 405 (10.4) & 1.78 (1.44 to 2.20$)$ \\
\hline $\begin{array}{l}\text { Gastrointestinal problems (eg, } \\
\text { gastritis, IBS, ulcers) }\end{array}$ & $217(12.2)$ & $426(18.9)$ & $934(24)$ & 1.55 (1.32 to 1.82$)$ \\
\hline Depression & $187(10.5)$ & $490(21.7)$ & $1148(29.5)$ & 2.07 (1.74 to 2.45$)$ \\
\hline Anxiety & $476(26.7)$ & $1108(49.1)$ & 3045 (78.3) & 1.84 (1.65 to 2.04$)$ \\
\hline Anger and irritability & $358(20.1)$ & $928(41.1)$ & 2406 (61.9) & 2.04 (1.77 to 2.35$)$ \\
\hline Other mental health problems & $12(0.7)$ & $54(2.4)$ & $256(6.6)$ & $3.45(1.80$ to 6.60$)$ \\
\hline Suicidal thoughts & $44(2.5)$ & $211(9.3)$ & $519(13.4)$ & 3.78 (2.68 to 5.32$)$ \\
\hline Sleep problems/insomnia & 479 (26.9) & $1137(50.4)$ & $288(74.1)$ & 1.87 (1.67 to 2.10$)$ \\
\hline Relationship problems & $187(10.5)$ & 458 (20.3) & $911(23.4)$ & 1.94 (1.63 to 2.30$)$ \\
\hline Frequent headaches & $242(13.6)$ & 432 (19.2) & 1027 (26.4) & 1.41 (1.19 to 1.65$)$ \\
\hline Minor colds & $492(27.6)$ & $509(22.5)$ & $5447(14)$ & 0.82 (0.73 to 0.92$)$ \\
\hline Recurring respiratory infections & 77 (4.3) & $143(6.3)$ & $306(7.9)$ & 1.47 (1.11 to 1.95$)$ \\
\hline \multicolumn{5}{|c|}{$\begin{array}{l}\text { The analysis following multiple imputation of missing values results in non-integer numbers of patients. We rounded these to integer values, } \\
\text { but report the percentage and relative risk as provided by the analysis. As a consequence, there may be slight discrepancies between the } \\
\text { percentages, relative risks and the reported patient numbers. } \\
\text { Please note that the past complaints group used retrospective information asking about worsening or onset of symptoms at the time of the } \\
\text { complaint, whereas the no and recent complaint groups were asked about the presence of symptoms in the past } 12 \text { months. }\end{array}$} \\
\hline
\end{tabular}




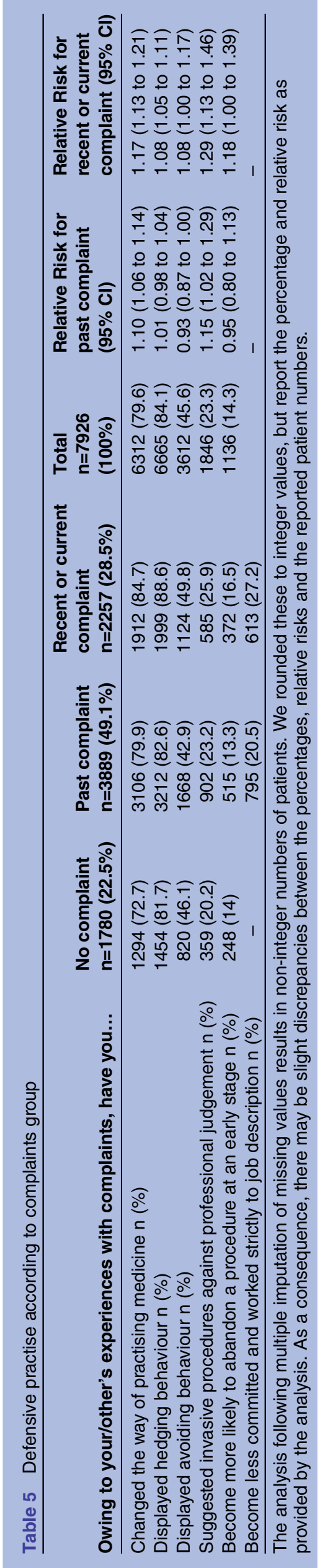

As with hedging, the multivariable analysis indicated that the odds of more severe avoidance increased with the length of time the investigation was underway (OR 1.01 per month, 95\% CI 1.01 to 1.02 ), and was higher for people with a recent or current complaint than for those with a past complaint (OR 1.20, 95\% CI 1.07 to 1.35 ; table 7). Avoidance was also increased when the investigation resulted in imposed retraining (OR 1.79, 95\% CI 1.0 to 3.09). Avoidance behaviour most severely increased when the complaint came from a patient group (OR 1.71, 95\% CI 1.02 to 2.87) or management (OR $1.59,95 \%$ CI 1.16 to 2.16), or when the complaint was anonymous (OR 1.58, 95\% CI 1.06 to 2.36). The type of complaint did not meaningfully influence the odds of more severe avoidance.

Overall, as a result of their experience of the complaints process, $23 \%$ of doctors reported suggesting invasive procedures against their professional judgement, and $14 \%$ reported becoming more likely to abandon a procedure at an early stage.

\section{Culture and time off work}

Twenty per cent (95\% C.I. $19 \%$ to $22 \%$ ) reported that they felt victimised because they had been a whistleblower for clinical or managerial dysfunction. Thirtyeight per cent (95\% C.I. $37 \%$ to $40 \%$ ) of people who had had a complaint, recently or in the past, reported feeling bullied during the investigation.

Sixty per cent (95\% CI $57 \%$ to $64 \%$ ) spent less than a week off work. However, $27 \%$ (95\% CI $24 \%$ to $30 \%$ ) of people with complaints spent more than a month off work.

\section{Opinions on changes to improve the system}

Of those doctors who gave a response, $85 \%$ felt that for managers to demonstrate a full up-to-date knowledge of procedure in relation to complaints if they were made responsible for them mattered quite a lot or a great deal in terms of improving the process. An equal number $(85 \%)$ felt that if a doctor is exonerated but has suffered financial loss during the process, then they should have the option to make a claim for recovery of lost earnings or costs and in addition that there should be complete transparency of any management communication about the subject of a complaint, and that access to such communications should be given to a doctor's representatives. Seventy-four per cent of respondents felt that it mattered quite a lot or a great deal if a complaint, found to be vexatious, from a clinical or managerial colleague, could be investigated and possible disciplinary measures taken. The full details of responses in relation to actions that could be taken to reduce the psychological impact of complaints processes are shown in online supplementary table S5.

\section{DISCUSSION}

We have shown that doctors who responded to our questionnaire who have recently received a complaint of any 
Table 6 Factors influencing hedging behaviour

\begin{tabular}{|c|c|c|c|}
\hline \multirow{2}{*}{$\begin{array}{l}\text { Effect } \\
\text { Length of investigation (per month) }\end{array}$} & \multirow{2}{*}{$\begin{array}{l}\text { Point estimate } \\
1.006\end{array}$} & \multicolumn{2}{|c|}{ 95\% Wald confidence limits } \\
\hline & & 1.002 & 1.011 \\
\hline Recent or current complaint (versus past complaint) & 1.331 & 1.193 & 1.485 \\
\hline \multicolumn{4}{|l|}{ Outcome of investigation } \\
\hline No fault/exonerated (yes vs no) & 1.051 & 0.676 & 1.633 \\
\hline Retraining imposed (yes vs no) & 1.622 & 0.913 & 2.885 \\
\hline Disciplinary action (yes vs no) & 0.815 & 0.433 & 1.532 \\
\hline Suspended from practise (yes vs no) & 0.557 & 0.289 & 1.075 \\
\hline Struck off from the register (yes vs no) & 0.583 & 0.754 & 1.761 \\
\hline The process was not clearly concluded (yes vs no) & 1.152 & 0.900 & 1.960 \\
\hline \multicolumn{4}{|l|}{ Where did the complaint come from } \\
\hline Trust (yes vs no) & 1.328 & 0.900 & 1.960 \\
\hline Medical colleagues (yes vs no) & 0.672 & 0.526 & 0.860 \\
\hline Management (yes vs no) & 0.797 & 0.581 & 1.094 \\
\hline Media (yes vs no) & 1.084 & 0.467 & 2.515 \\
\hline Patient group (yes vs no) & 1.495 & 0.906 & 2.464 \\
\hline Other healthcare professional (yes vs no) & 1.047 & 0.798 & 1.375 \\
\hline \multicolumn{4}{|l|}{ Patient (yes vs no) } \\
\hline For informal complaint & 3.155 & 2.172 & 4.584 \\
\hline For formal complaint & 2.180 & 1.670 & 2.846 \\
\hline For SUI & 1.212 & 0.826 & 1.778 \\
\hline For GMC referral & 1.670 & 1.207 & 2.311 \\
\hline Anonymous (yes vs no) & 1.362 & 0.922 & 2.012 \\
\hline \multicolumn{4}{|l|}{ Type of complaint } \\
\hline \multicolumn{4}{|l|}{ Formal complaint versus informal complaint } \\
\hline Complaint did not come from a patient & 1.521 & 1.034 & 2239 \\
\hline Complaint came from a patient & 1.051 & 0.903 & 1.223 \\
\hline \multicolumn{4}{|l|}{ SUI versus informal complaint } \\
\hline Complaint did not come from a patient & 2.097 & 1.311 & 3.352 \\
\hline Complaint came from a patient & 0.805 & 0.648 & 1.002 \\
\hline \multicolumn{4}{|l|}{ GMC referral versus informal complaint } \\
\hline Complaint did not come from a patient & 1.776 & 1.164 & 2.709 \\
\hline Complaint came from a patient & 0.940 & 0.757 & 1.168 \\
\hline
\end{tabular}

kind are $77 \%$ more likely to suffer from moderate to severe depression than those who have never had a complaint. They also have double the risk of having thoughts of self-harm and double the risk of anxiety. Welfare is lowest when the complaint involves referral to the GMC. Doctors with a recent or current complaint also reported that they suffered from an increased likelihood of cardiovascular and gastrointestinal disorders, depression, anxiety, anger and irritability, suicidal thoughts, sleep difficulty, relationship problems and frequent headaches than people who had not been through a complaints process. In many cases, these problems persisted. We have also shown that $80 \%$ of doctors answering the survey reported changing the way they practised as a result of either complaints against themselves, or after observing a colleague go through a complaints process. The majority $(84 \%)$ of doctors reported hedging behaviour in response to a complaint (ie, increased defensive practise), while many (46\%) admitted avoidance. A further important finding was that many doctors who had a complaint $(20 \%)$ felt they were victimised after whistleblowing, 39\% reported that they felt bullied when they were going through the process and $27 \%$ had more than a month off work.

A strength of the study is that, to our knowledge, it is one of the largest reported on the subject involving 10930 respondents with 7926 completing the survey. It is certainly the largest relating to doctors in the UK. We think it is critical that respondents were guaranteed at the outset that their responses were anonymous and untraceable, so we think the respondents are likely to have been open about their opinions. Furthermore, we have obtained quantitative data on the mental well-being of doctors using validated questionnaires. It is also important to note that we have collected responses from doctors who have not experienced a complaint but observed the impact on others. On the one hand, this gives insight into the impact of observing a colleague going through a complaints process, however, it also means that the 'no complaints' group may have a higher overall level of psychological morbidity than if doctors could be isolated from complaints processes completely. 
Table 7 Factors influencing avoidance behaviour

\begin{tabular}{lllr}
\hline OR estimates for avoiding & & & \\
\hline Effect & Point estimate & $95 \%$ Wald confidence limits \\
\hline Length of investigation (per month) & 1.011 & 1.006 & 1.016 \\
Recent or current complaint (vs past complaint) & 1.201 & 1.069 & 1.350 \\
Outcome of investigation & & & 1.340 \\
$\quad$ No fault/exonerated (yes vs no) & 0.893 & 0.594 & 3.092 \\
Retraining imposed (yes vs no) & 1.787 & 1.033 & 2.152 \\
Disciplinary action (yes vs no) & 1.211 & 0.682 & 2.008 \\
Suspended from practise (yes vs no) & 1.066 & 0.566 & 3.305 \\
Struck off from the register (yes vs no) & 0.626 & 0.119 & 1.796 \\
$\quad$ The process was not clearly concluded (yes vs no) & 1.202 & 0.805 & 1.968 \\
Where did the complaint come from & & & 1.826 \\
Trust (yes vs no) & 1.338 & 0.910 & 1.670 \\
Medical colleagues (yes vs no) & 1.439 & 1.134 & 2.161 \\
Patient (yes vs no) & 1.364 & 1.114 & 1.972 \\
Management (yes vs no) & 1.585 & 1.163 & 2.866 \\
Media (yes vs no) & 0.866 & 0.380 & 1.731 \\
Patient group (yes vs no) & 1.708 & 1.019 & 2.360 \\
Other healthcare professional (yes vs no) & 1.326 & 1.015 & 1.323 \\
Anonymous (yes vs no) & 1.580 & 1.057 & 1.368 \\
Type of complaint & & & 1.203 \\
$\quad$ GMC referral (vs informal complaint) & 1.082 & 0.885 &
\end{tabular}

Hence the relative risks in the paper may be underestimated. A significant limitation of the study is that the response rate was $11.4 \%$, accordingly the findings must be interpreted with caution due to the possibility of ascertainment bias. What constitutes an acceptable response rate is a subject of debate, however, our response rate is clearly low. ${ }^{19}$ We believe this is inevitable when asking doctors to comment on disciplinary processes and in particular on their regulator. Even if we take the view that the respondents are a selected group, they still demonstrate that a very considerable number of doctors are significantly impacted by complaints processes and practise defensively. It must also be remembered that doctors who have been most traumatised by the complaints process may have felt unable to take part in the survey and a small number are known to have committed suicide. Furthermore, those no longer on the register (eg, if they have changed profession or been erased from the register) are unlikely to be members of the BMA and so would not have been contacted. As some questions involved remembering past events, the possibility of recall bias for some answers must also be considered. For a number of questions there were missing responses. However, we have considered this issue by using multiple imputation and were reassured when we found no essential differences between the conclusions that would be drawn using complete cases compared to those where missing data have been imputed.

As with any cross-sectional survey we must be careful when considering the findings, as we cannot show causation. It is possible that doctors with depression, anxiety and suicidal ideation are more likely to have complaints made against them, similarly, being complained against may be the causative factor rather than the processes themselves. However, this still means the information presented is important, as if we take the former view, it means those going through complaints processes are part of a vulnerable group that needs support. This was illustrated in a recent study that reported that sick doctors under investigation stated that the processes and communication style employed by the GMC were often distressing, confusing and perceived to have impacted negatively on their mental health and ability to return to work. ${ }^{20}$

It is interesting that our findings are similar to a questionnaire-based study of surgeons in the USA examining the emotional toll of malpractise lawsuits. This study found significantly more depression and burnout in surgeons who had recently been exposed to a lawsuit and highlighted the association between burnout and the likelihood of making a medical error. ${ }^{4}$

We found that $10 \%$ of doctors responding to the survey who have had a recent complaint have had thoughts of self-harm and are over twice as likely to have had such thoughts compared to doctors who had not personally experienced a complaint. When referral to the GMC is looked at in isolation, the number of doctors who reported suicidal ideation reached $15.3 \%$, while $26.3 \%$ had moderate to severe depression and $22.3 \%$ had moderate to severe anxiety on the basis of 
two validated instruments. Even set against the limitations of the study we have highlighted above, these findings are concerning. In a recent feature article in the $B M J$, Dyer reported on the high number of suicides associated with GMC proceedings. ${ }^{3}$ Our results support the view that these proceedings have a disproportionate impact on doctors, especially as the vast majority of doctors who are referred to the GMC are found to have no significant case to answer. ${ }^{2}$ However, the GMC is at the apex of what amounts to a 'complaints pyramid' and our data show similar significant psychological morbidity for doctors across the entire spectrum of complaints procedures.

The incidence of feeling victimised following whistleblowing (20\%) and bullying (38\%) will be a concern to those trying to build a culture in the UK National Health Service (NHS) where it is safe to speak out about clinical and managerial concerns. The Francis report highlighted the dysfunctional culture that is prevalent in many NHS organisations. ${ }^{21}$ Other reports have also highlighted serious concerns about the pressures that may be placed on hospital staff. ${ }^{22}$ Given the large numbers involved, our study supports the view that whistleblowing in the NHS is often not a safe action, that bullying is not uncommon and that these problems are not isolated events.

The GMC exists to protect patients and the public. This is also the aim of other types of complaints processes with the overall purpose being to learn from mistakes and improve the performance of everyone taking part in patient care. However, as with all interventions, there may be unforeseen consequences. Previously Jain and $\operatorname{Ogden}^{7}$, in a qualitative study, reported that many GPs practise defensively following a complaint. Our data also show the vast majority of doctors who took part in the study reported engaging in defensive practise. This included carrying out more tests than necessary, overreferral, overprescribing, avoiding procedures, not accepting high-risk patients and abandoning procedures early. Nash et at $t^{23}$ have also reported high levels of defensive practise. In their study, which had a higher response rate of $36 \%, 43 \%$ of doctors reported that they referred more patients, $55 \%$ ordered more tests and $11 \%$ stated they prescribed more medications than usual in response to medicolegal concerns. In a further report, the same authors showed that doctors working in high-intervention areas of medicine are more likely to be the subject of medicolegal complaints. ${ }^{24}$ Defensive practise in such specialties may be particularly concerning.

These behaviours are not in the interest of patients and may cause harm, while they may also potentially increase the cost of healthcare provision. By far the majority of doctors who are reported to the GMC are not found to have a significant case to answer, ${ }^{2}$ as is probably the case with other lower level complaint investigations. It therefore does not seem unreasonable to argue that as they currently function, GMC inquiries may do more overall harm than good in terms of patient care. As the 'complaints pyramid' is descended it is possible this balance may improve, although we found defensive practise across the entire spectrum of complaints processes.

While we fully acknowledge the limitations associated with any study of this type, we believe our findings have implications for policymakers. Procedures must exist to enable patients to make a complaint about their care, for professionals to raise concerns about standards of practise and for serious untoward events to be investigated. However, a system that is associated with high levels of psychological morbidity among those going through it is not appropriate as either the subjects of such procedures are vulnerable at the outset or are suffering such morbidity as a direct result of the investigations themselves. Most importantly, a system that leads to so many doctors practising defensive medicine is not good for patients. A further concern for patient care is the association between doctor's distress, burnout and decreased empathy with perceived medical errors. ${ }^{6}$

When asked how the complaints process could be improved, doctors indicated that what mattered to them was that the process should be transparent and that staff responsible for investigating complaints should be up-to-date and competent. There was also a clear feeling that in the event of a complaint being shown to be vexatious, there should be disciplinary consequences if this related to colleagues, or the option for financial redress in the event it related to patients. Concerns about the lack of redress associated with vexatious complaints have been raised in the $B M J$ before. ${ }^{25}$ This highlights the inherent tension in the system whereby an apparent 'whistleblower' may be perceived as a vexatious complainant by a colleague.

We have shown that doctors who responded to our questionnaire and experience or observe complaints processes exhibit high levels of psychological morbidity including severe depression and suicidal ideation. These effects are greatest when the process involves the GMC. In addition, the majority of these doctors exhibit hedging and avoidance; both these behaviours may be damaging to patient care and be contrary to the professed aims of these processes.

\section{Author affiliations}

${ }^{1}$ Queen Charlotte's \& Chelsea Hospital, Imperial College, London, UK ${ }^{2} \mathrm{KU}$ Leuven Department of Development and Regeneration, Leuven, Belgium ${ }^{3}$ Department of Obstetrics and Gynaecology, University Hospitals Leuven, Leuven, Belgium

${ }^{4} \mathrm{KU}$ Leuven Department of Electrical Engineering-ESAT, STADIUS Center for Dynamical Systems, Signal Processing and Data Analytics, Leuven, Belgium

${ }^{5} \mathrm{KU}$ Leuven iMinds Future Health Department, Leuven, Belgium

${ }^{6}$ Doctors for Doctors, British Medical Association, London, UK

${ }^{7}$ LUCAS, KU Leuven, Leuven, Belgium

${ }^{8}$ South London and Maudsley NHS Foundation Trust, London, UK

Acknowledgements The authors would like to thank Mr Christoph Lees (Imperial College London) and Mr Magnus Boyd (Hill Dickinson LLP solicitors) contributed to receiving feedback on the contents and design of the questionnaire. The authors would like to thank all clinicians who commented on the initial versions of the survey. 
Contributors TB conceived of the original idea for the study, interpreted results, drafted the paper and is overall guarantor. MJ designed the questionnaire, obtained ethical approval, contributed to the preparation of the data set, interpreted results and contributed to drafts of the paper. LW and BVC carried out the statistical analysis and contributed to drafts of the papers. MP contributed to the study design, interpretation of results and commented on drafts of the paper. DT and CVA contributed to interpretation of results and commented on drafts of the paper. All authors approved the final version of the manuscript.

Funding TB is supported by the National Institute for Health Research (NIHR) Biomedical Research Centre based at Imperial College Healthcare NHS Trust and Imperial College London. The views expressed are those of the author(s) and not necessarily those of the NHS, the NIHR or the Department of Health. LW is supported by a PhD grant of the Flanders' Agency for Innovation by Science and Technology (IWT Vlaanderen). DT is a Senior Clinical Investigator of the Research Foundation-Flanders (FWO).

Competing interests MP is head of the BMA doctors for doctors unit and so receives payment from the BMA.

Ethics approval Ethical approval was sought and obtained from King's College London, Psychiatry, Nursing and Midwifery Research Ethics Subcommittee (PNM/12/13-22).

Provenance and peer review Not commissioned; externally peer reviewed.

Data sharing statement No additional data are available.

Open Access This is an Open Access article distributed in accordance with the Creative Commons Attribution Non Commercial (CC BY-NC 4.0) license, which permits others to distribute, remix, adapt, build upon this work noncommercially, and license their derivative works on different terms, provided the original work is properly cited and the use is non-commercial. See: http:// creativecommons.org/licenses/by-nc/4.0/

\section{REFERENCES}

1. White C. Complaints against doctors continue to rise. BMJ Careers 30 September 2013. http://careers.bmj.com/careers/advice/ view-article.html?id=20014782 (accessed 25 Nov 2013).

2. General Medical Council. Fitness to Practise Annual Statistics Report 25th September 2012. http://www.gmc-uk.org (accessed on 25 Nov 2013).

3. Dyer C. GMC and vulnerable doctors: too blunt an instrument? BMJ 2013;347:f6230.

4. Balch CM, Oreskovich MR, Dyrbye LN, et al. Personal consequences of malpractice lawsuits on American surgeons. J Am Coll Surg 2011;213:657-67.

5. Shanafelt TD, Balch CM, Dyrbye L, et al. Special report: suicidal ideation among American surgeons. Arch Surg 2011;146:54-62.
6. West CP, Huschka MM, Novotny PJ, et al. Association of perceived medical errors with resident distress and empathy: a prospective longitudinal study. JAMA 2006;296:1071-8.

7. Jain A, Ogden J. General practitioners' experiences of patients complaints: qualitative study. BMJ 1999;318:1596-9.

8. Bark $P$, Vincent $C$, Olivieri $L$, et al. Impact of litigation on senior clinicians: implications for risk management. Qual Health Care 1997;6:7-13.

9. Schat AC, Kelloway EK, Desmarais S. The Physical Health Questionnaire: construct validation of a self-report scale of somatic symptoms. J Occup Health Psychol 2005;10:363-81.

10. Studdert DM, Mello MM, Sage VM, et al. Defensive medicine among high-risk specialist physicians in a volatile malpractice environment. JAMA 2005;293:2609-17.

11. Nash L, Walton M, Daly M, et al. GPs' concerns about medico legal issues: how it affects their practice. Aust Fam Physician 2009;38:66-70.

12. Summerton N. Positive and negative factors in defensive medicine: a questionnaire study of general practitioners. BMJ 1995;310:27-9.

13. Spitzer R, Kroenke K, Williams J. Validation and utility of a self-report version of PRIME-MD: the PHQ Primary Care Study. JAMA 1999;282:1737-44.

14. Kroenke K, Spitzer RL, Williams JBW. The PHQ-9: validity of a brief depression severity measure. J Gen Intern Med 2001;16:606-13.

15. Spitzer RL, Kroenke K, Williams JBW, et al. A brief measure for assessing generalized anxiety disorder: the GAD-7. Arch Intern Med 2006;166:1092-7.

16. Raghunathan TW, Lepkowksi JM, Van Hoewyk J, et al. A multivariate technique for multiply imputing missing values using a sequence of regression models. Surv Methodol 2001;27:85-95.

17. Rubin DB. Multiple imputation for nonresponse in surveys. NY: Wiley, 1987.

18. IVEware: Imputation and Variance Estimation Software. http://www. isr.umich.edu/src/smp/ive/ (accessed 12 Aug 2013).

19. Baruch Y. Response rate in academic studies-a comparative analysis. Hum Relations 1999;52:421-38.

20. Brooks SK, Del Busso L, Chalder T, et al. 'You feel you've been bad, not ill': Sick doctors' experiences of interactions with the General Medical Council. BMJ Open 2014;4:e005537.

21. Report of the Mid Staffordshire NHS Foundation Trust Public Inquiry February 2013. Chaired by Robert Francis QC. http://www. midstaffspublicinquiry.com/report (accessed 25 Nov 2013).

22. Care Quality Commission recommends Essex hospital trust is put into special measures 5 November 2013. http://www.cqc.org.uk/ media/care-quality-commission-recommends-essex-hospital-trustput-special-measures (accessed on 25 Nov 2013)

23. Nash LM, Walton MM, Daly MG, et al. Perceived practice change in Australian doctors as a result of medicolegal concerns. Med J Aust 2010;193:579-83.

24. Nash LM, Kelly PJ, Daly MG et al. Australian doctors' involvement in medico-legal matters: a cross-sectional self-report study. Med J Aust 2009;191:436-40.

25. Marcovitch $\mathrm{H}$. GMC must recognise and deal with vexatious complaints fast. BMJ 2002;324:167-8. 